\title{
Electrification Solution with Supercapacitor Storage of a Bow Thruster for River Tugboat
}

\author{
Alexandre De Bernardinis ${ }^{1}$ and Jeff Moussodji ${ }^{2}$ \\ 1. SATIE/IFSTTAR, The French Institute of Science and Technology for Transport, Development and Networks, 25 Allée des \\ Marronniers, Versailles 78000, France \\ 2. University of Sherbrooke (UdeS), 2500 Boulevard de l'Université, Sherbrooke, Québec J1K 2Rl, Canada
}

\begin{abstract}
Bow thrusters usually are hydraulic and mechanically driven engines, used for the positioning maneuvers of River and sea boats. The peculiarity of these systems operating on short time intervals is their low rate of use (approximately $2 \%$ ) but requiring maximal power. The main purpose of the work is to propose an innovative electrical hybridization of the bow thruster for a river tugboat. This electrification solution enables the bow thruster to operate with no-emissions, reduced noise and is a subsystem of green ship. Main challenge is to manage high torque and low speed requirements of the bow thruster system during the positioning maneuvers, by adding a dynamic electrical storage system, based on high capacitance value Supercapacitors, and in association with the electrified propeller motor. The knowledge concerns hybrid electrification, involving new-technology elements, energy storage based on supercapacitors, the high amplitude low speed torque control strategy. With fully reversible electrical motorization, the propeller is able to operate for both direct-reverse ways of rotation. Proposed electrical solution would hence provide large expected benefits in terms of energy efficiency, compactness, weights, costs, and contribute to a more eco-friendly ship. Numerical simulation and first results on laboratory test bench validate the proposed electrification concept.
\end{abstract}

Key words: Energy storage, marine navigation, permanent magnet machines, supercapacitors, torque control.

\section{Introduction}

In recent years, worldwide eco-activities relating to reduce collective greenhouse gas emissions (GHGs) due to environmental concerns have increased and have led many countries to take an interest in the production of carbon-free energies and to achieve greater autonomy through reducing and/or eliminating a country's dependence on oil. Thus, many key sectors of activities relative to low-carbon emissions such as land transportation (electric, hybrid vehicles), but also, marine transportation (maritime or river vessels) have been affected. In this study, special attention will be paid to maritime transport. Even if the marine transportation industry contribution to global $\mathrm{CO}_{2}$ emissions is small compared to land transportation, this industry significantly contributes to emissions of

Corresponding author: Alexandre De Bernardinis, researcher, research fields: transport system, fault tolerant resilient electric, mechatronic systems and energy storage. pollutants. In fact, the on-board diesel engines consume fuel oil, diesel oil or gas oil. As a result, not only the $\mathrm{CO}_{2}$ rejection, but also the $\mathrm{SO}_{2}$, the $\mathrm{NO}_{\mathrm{X}}$ and carbon particles among various other pollutants are emitted in smaller quantities [1].

Currently, with regard to the maritime transportation, there is an increased interest in hybrid propulsion and, in the time, full electric propulsion has revealed as a potential solution to these concerns. This can be seen today by more and more modern ships which try to have an all-electric structure [2]. However, electrical installations are already present in any ships, from powering of communication and navigation equipment, alarm and monitoring systems, running of motors for pumps, fans or winches, to high power installation for electric propulsion. The lighting is also an important consumer powered by the generating system, in particular during evening or night's maneuvers and by intermittence operating. But, with the possibility to control electrical motors with variable speed in a large 
power range with compact, reliable and cost competitive solutions, the use of electrical propulsion has emerged in new application areas [3, 4]. Moreover, ships with electric propulsion tend to have more system functionality implemented in integrated and smart automation systems. This all-electric ships concept opens up for an increasing use of power electronics devices and integrated systems, in order to operate safely and cost efficiently [5, 6]. Such concepts are today applied in an increasing number of ship applications [7, 8]. The all-electric ships concept brings benefits not only in the required ability to conduct complex marine operations, flexibility in operational profile concerning transit, station keeping, maneuverability, dynamic performance, noise, safety focus, but also, in reduction cost effectiveness, environmental and energy-saving point of view [9]. It is underlined that the openness and flexibility provided by the all-electric ships concept through the integration of diverse technologies (power converters, electric motors, energy storage systems ...) provide a boost to innovation, opening the marine sector market to small and innovative companies.

Even so, the fully all-electric ship is not yet quite over. Indeed, many shipboard subsystems such as capstans, rudders, stabilizing fins, bow thrusters, etc., are still yet driven by conventional hydrostatic actuators [9, 10]. Moreover, the hydraulic drive technology suffers from major drawbacks, like low efficiency, high maintenance, oil pipe leaks, heavy weights and too expensive operating costs $[10,11]$. The all-electric ship concept therefore represents a major interest and lies on the electrification of each subsystem mentioned above. Of course, the extensively electrified ship, with most of the onboard subsystems being electrically powered, seems to be as the most interesting "green" solution [10]. Within this frame, the research carried on electrification of the boats should meet new significant challenges, like the objective of having a full efficient solution, reliability of the power converters and electric components, safety issues, electric sources management ...[11]. Today, in the most of proposed environmentally friendly design concepts, thermal engines are still present in association with generators or through hybridization, to provide the full propulsion power. Nevertheless, as it has been shown in previous work, it is feasible to fully electrify some subsystems of the boat [10].

In this introductory part, we hereafter detail a short literature survey about electrification in ship systems and all-electric ship challenges [12-15], and about active thrusters with dynamic positioning (DP) capability criteria $[16,17]$ and controlled towed and self-propulsive systems [18, 19]. Next section is dedicated to bow thrusters.

According to G. Sulligoi, and A. K. Rathore [12], shipboard electrical applications are increasing in marine systems, from generators to users (propulsion, thrusters, handling, air conditioning, auxiliaries, actuators, and so on). Electrical applications are largely utilized in many classes of "all electric" and "more electric" ships, such as cruise liners, naval vessels, supply vessels, yachts, offshore energy vessels, platforms, drilling rigs, cable/pipe-layers, ice-breakers, inland waterways, and so on. Beside the development of electrical applications, industrial competition requires to reduce volume, weight, and emissions in order to cut ship capital expenditures and operating costs. A revision (or replacement) to the existing electric power system architectures is regarded as a promising way to meet such demands. In this view, power electronics become a key enabling technology along with advanced grid controls, energy storage systems, and by-wire-actuators to make electrical energy utilization more efficient and rational. For G. Sulligoi et al. [13], electrical propulsion is not a novel concept in marine systems. However, the availability of power electronic converters has proved to be the Key Enabling Technology for electrification of large ships. The aim of work in Ref. [13] is, hence, to demonstrate why research on design methods is as important as a technological one, on the basis of the 
needs concerning the design, integration, and management of future "integrated electrical and electronic power systems" (power systems with power conversion quota approaching 100\%). In Ref. [14], V. Bucci et al. expose a novel design of a push-boat for barges convoys and optimized for the Rhine-Danube corridor. To this aim, a hybrid parallel electric propulsion system has been adopted with the perspective to define an eco-friendly vessel. This work is to be intended as the early stage in the proof of concept for commercial technologies useful for the electrification of push-boats employed in inland waterway navigation. Specifically, the optimal design solution is highlighted by evaluating proper attribute weights, which determine the degree of closeness among possible solution and the design target. Authors in Ref. [15] show hybrid power systems with DC distribution are being considered for commercial marine vessels to comply with new stringent environmental regulations, and to achieve higher fuel economy. In this study, detailed efficiency analysis of a shipboard DC hybrid power system is carried out. An optimization algorithm is proposed to minimize fuel consumption under various loading conditions. The studied system includes diesel engines, synchronous generator-rectifier units, a full-bridge bidirectional converter, and a Li-Ion battery bank as energy storage. In order to evaluate potential fuel saving provided by such a system, an online optimization strategy for fuel consumption is implemented. An Offshore Support Vessel (OSV) is simulated over different operating modes using the online control strategy. The resulted consumed fuel in the simulation is compared to that of a conventional AC power system, and also a DC power system without energy storage. The results show that while the DC system without energy storage provides noticeable fuel saving compared to the conventional AC system, optimal utilization of the energy storage in the DC system results in twice as much fuel saving. Finally, J. Ling-Chin, and A. P. Roskilly [20] have proposed an investigation on a conventional and retrofit power plant on-board a cargo ship from a sustainability perspective completed by a comparative life cycle assessment for marine power systems [21].

In this context, and in the framework of the French project PROMOVAN (Innovative Propulsion and Motorization for River Boats) coordinated by VNF (Voies navigables de France) Company, the paper aims to propose a solution regarding the electrification of a ship subsystem, the bow thruster.

\section{Section on Bow Thrusters}

We first suggest making a short focus on bow thrusters, how they work and why are they so important for a ship. For efficient maneuverability of a ship, the main propulsion system is not enough. Today, every power ship is provided with bow thrusters to ensure fine maneuverability in confined water. In the bottom of the ship at the bow, there are two propeller type structures embedded in the ship's body. These structures are known as bow thrusters and represent the propulsion devices fitted to improve maneuverability of the ship. They enable easy movement of a ship in confined areas and also for positioning, docking and undocking purposes. A bow thruster is therefore a key subsystem which is only used in few operations during short time intervals (of a few seconds). The bow thruster unit is mainly controlled from the bridge and is most effective to be controlled when the ship is stationary. So, this application requires high torque values and low speed [10]. Power is usually provided by conventional hydraulic systems as discussed earlier, but we meet more and more often the electrical bow thruster in the small vessels. The power unit having its propeller motor is an auxiliary machine, and it is independent from the main propulsion of the boat, and enables some specific maneuvers on the river even if the main propulsion motor system is not active. It will be a real issue to propose an electric or hybrid electric solution to the bow thruster, in the sense of this partial electrification of the vessel contributes to a certain level to the all-electric ship concept and their important 
profits listed above. This is also, the first time, regarding our feedback knowledge, that an electric model of the propulsion chain of a bow thruster is proposed, and as we have previously seen, all electric ship concept passes through the electrification of each ship subsystem.

The main objectives to electrify subsystems of the river boat (in our case the bow thruster), are to achieve a more environmental friendly solution, with reduced $\mathrm{CO}_{2}$ emissions, but also minimize the global weight of the system, noise reduction and improved dynamic performance with the use of high speed transient electrical storage devices and components. To this end, this paper proposes two innovative technical solutions to achieve the bow thruster electrification or hybridization. The study will be detailed for one of these two candidate solutions.

- A 3-phase diesel generator set associated with the alternator is coupled with a reversible converter $\mathrm{AC} / \mathrm{DC}$ fed by a battery, as the electric sources are in direct connection to the electric bow thruster, see Fig. 1a.

- The adaptation of a 3-phase DC/AC inverter topology powered by the battery onboard DC bus, coupled with an electrical energy storage system (Supercapacitors) in order to supply an electric bow thruster (motor-propeller), as it can be seen in Fig. 1b.

The first solution is dependent on the electrical characteristic of the diesel engine and battery performance. Indeed, the frequency of the bow thruster motor directly depends on the operating speed of the diesel engine even if the PWM (Pulse Width Modulation) voltage inverter will try to compensate this drawback thanks to an appropriate control strategy. As a consequence, this solution is less flexible for the control of the motor speed compared to the second one which does not involve the use of diesel engine and hence offers more degree of freedom for the control level.

Hence, in this paper, only the second candidate solution will be investigated, and description of the system modeling and proposed control strategy will be underlined.

\section{Load Profiles Issued from Real Data Monitoring of Bow Thruster's Hydraulic Pump}

In this part, we first present in Fig. $2 \mathrm{~b}$ and Table 1 an illustration of the French CFT tugboat (CFT: Compagnie Fluviale de Transport, partner of the PROMOVAN project), and a table of experimental data recording on a French tugboat during river gate crossing. French CFT tugboat is a boat that maneuvers vessels by pushing or towing them. Tugboats move vessels that either should not move by themselves, such as ships in a crowded harbor or a narrow canal.

Generally, bow thrusters are transverse thrusters placed at the forward and aft end of the boat. The

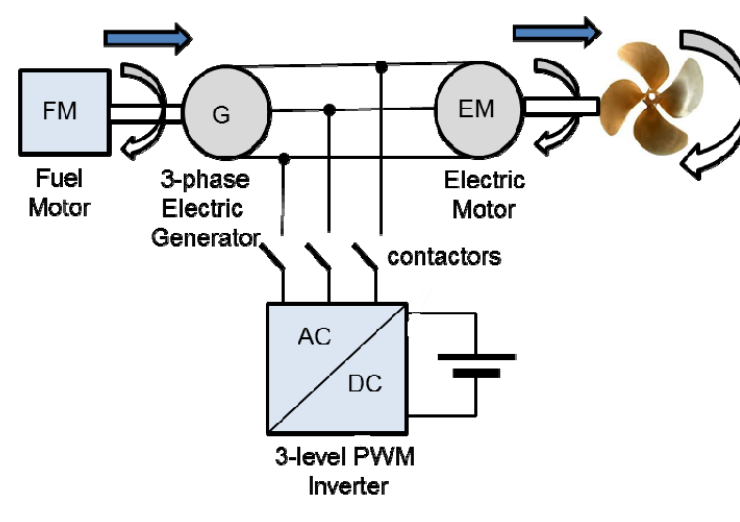

(a)

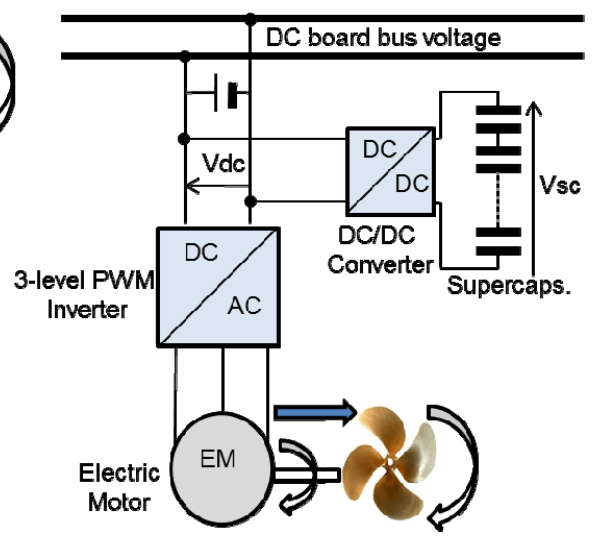

(b)

Fig. 1 Diagram of bow thruster energetic propulsion chain, (a) Hybrid conception; (b) Full electric solution. 


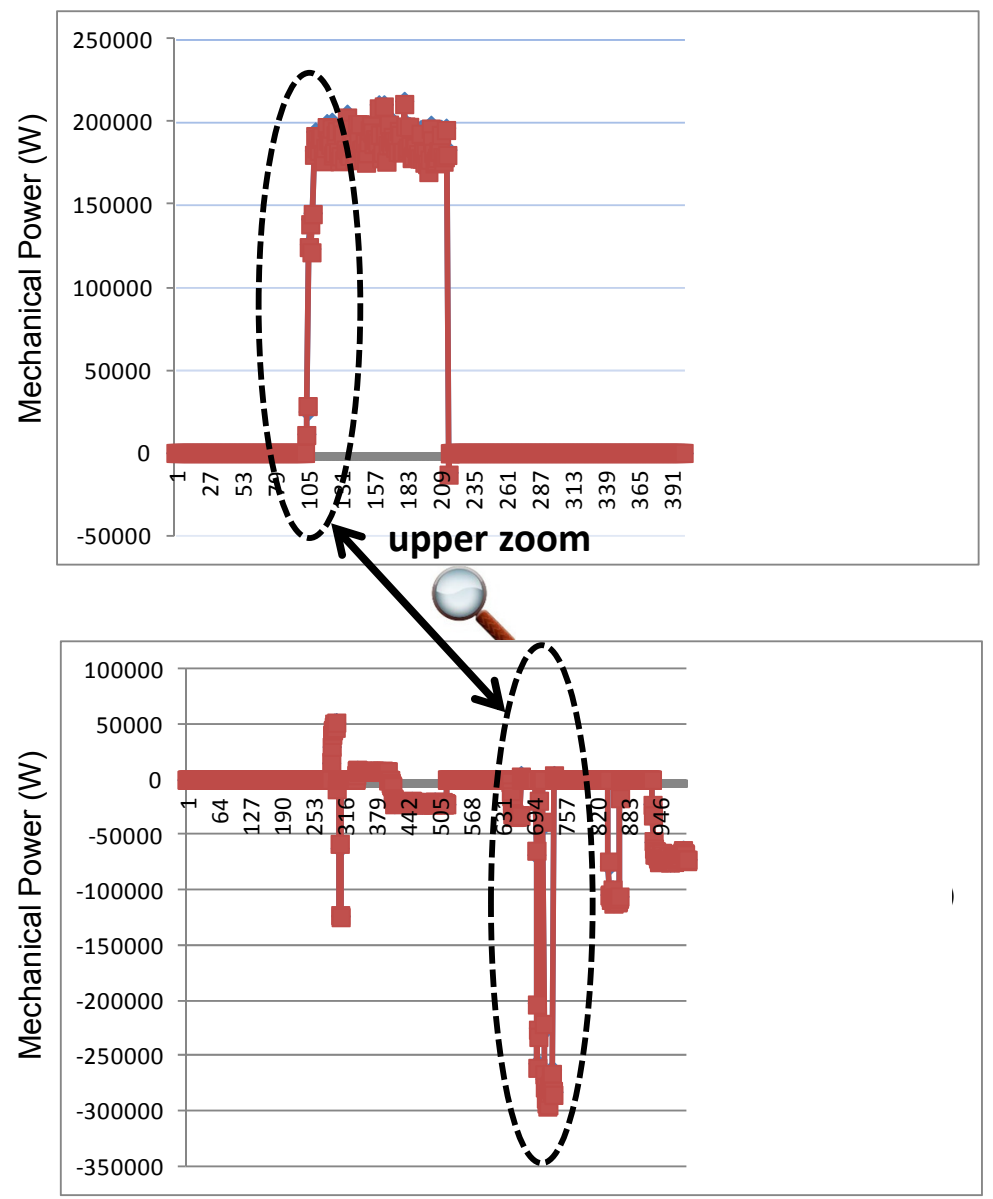

(a) Mechanical power profile (P_F and P_B) (Watt) of hydraulic pump

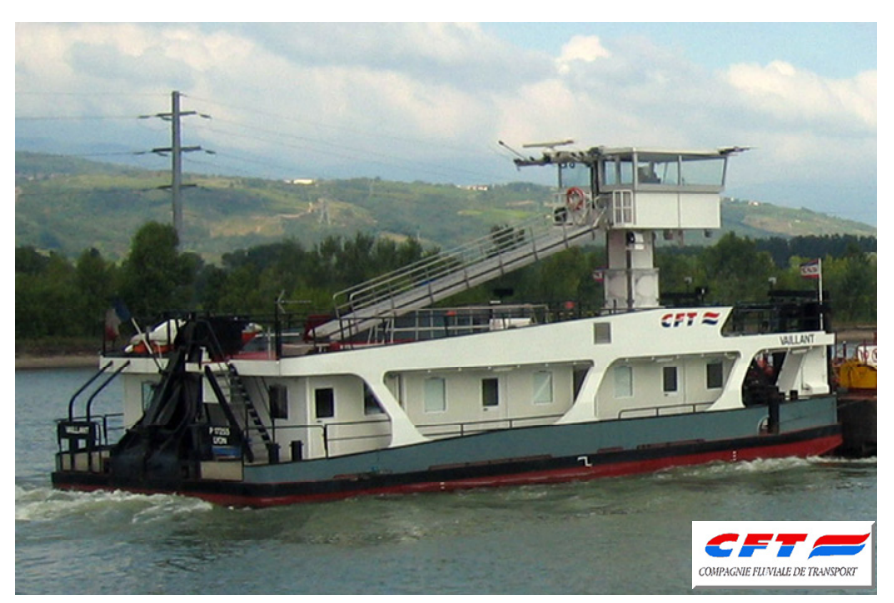

(b) French CFT Tugboat

Fig. 2 (a) Real data showing the power profile of the hydraulic pump of the bow thruster (Source: Monitored data from CEA); (b) French tugboat illustration from CFT; Table 1: Data recording on French CFT tugboat.

thruster placed in the forward end is known as the bow thruster, and the one placed in the aft is known as the stern thruster. Bow thrusters are type of propellers, which are smaller in size and which help in better maneuverability of the ships at lower speeds. They are generally used for maneuvering the vessel near the coastal waters or while entering or leaving a harbor. Bow thrusters help in assisting tugboats in berthing the 
Table 1 (Up and bottom) hydraulic pump data.

\begin{tabular}{lllll}
\hline$D_{\mathrm{F}}(\mathrm{L} / \mathrm{mn})$ & $D_{\mathrm{B}}(\mathrm{L} / \mathrm{mn})$ & $P_{\mathrm{F}}($ bar $\times 10)$ & $P_{\mathrm{B}}($ bar $\times 10)$ \\
\hline 1 & 0.9 & 228 & 172 & \\
1 & 0.6 & 232 & 172 & \\
0.9 & 0.4 & 228 & 176 & \\
\hline$D_{\mathrm{F}}\left(\mathrm{m}^{3} / \mathrm{sec}\right)$ & $D_{\mathrm{B}}\left(\mathrm{m}^{3} / \mathrm{sec}\right)$ & $P_{\mathrm{F}}-P_{\mathrm{B}}(\mathrm{Pa})$ & $P_{-} \mathrm{F}(\mathrm{W})$ & $P_{-} \mathrm{B}(\mathrm{W})$ \\
\hline $1.6667 \mathrm{E}-5$ & 0.000015 & 560000 & 9.333333 & 8.4 \\
$1.6667 \mathrm{E}-5$ & 0.00001 & 600000 & 10 & 6 \\
0.000015 & $6.66667 \mathrm{E}-6$ & 520000 & 7.8 & 3.466667 \\
\hline
\end{tabular}

ship without wasting time. This saves a lot of money for the shipping company because of lesser stay of the ships in the ports. Tugboats are powerful for their size and strongly built, and some are ocean-going. Today most tugboats, alike French CFT ones, have diesel engines, and their bow thruster is hydraulic systems. However hydraulic driven thrusters occur with many leakage problems. Also, with diesel driven bow thrusters, the amount of maintenance required is more and every time before starting an operator needs to control the thrusters.

The context of the research consists to substitute the diesel-hydraulic system by a full electric one adding an energy storage system, in this study a super-capacitor bank, in order to propose an environmental-friendly solution, and with high efficiency. The energy storage system enables to mitigate the effect of thruster power demand on the generating system.

Load profiles illustrate the operating instants of the bow thruster. From the accurate knowledge of load profiles issued from monitoring of the conventional hydraulic pump feeding the bow thruster, real data showing the mechanical power profile of the hydraulic pump of the bow thruster, are shown in Fig. 2a. This single data measurement is enough relevant because they enable to know the dynamic power constraints for the bow thruster, and permit to size the electrical motor solution. In Fig. 2a upper part, a zoom on the mechanical power transient (absolute value) is shown.

One shaft of the diesel machine installed on French CFT tugboats provides mechanical power to the hydraulic pump which feeds the bow thruster. Hydraulic profile corresponds to the maximal mechanical power (hundreds of $\mathrm{kW}$ ) demand during short periods of times (several seconds) required by the boat maneuvers. Real profiles monitored on-board are provided for the French CFT tugboat's bow thruster.

Table 1 presents two table sections, with several rows: Upper values, hydraulic pump forward $\left(D_{\mathrm{F}}\right)$ and backward flows $\left(D_{\mathrm{B}}\right)$ (in $\left.\mathrm{L} / \mathrm{mn}\right)$, and forward $\left(P_{\mathrm{F}}\right)$ and backward $\left(P_{\mathrm{B}}\right)$ pressures (in bars $\left.\times 10\right)$ are issued from real on-board numerical data recording, during the positioning maneuver of the tugboat when passing through a gate on the Rhône river along and until the Mediterranean Sea. The forward mechanical power $P_{-} \mathrm{F}$ (W) and back power $P_{\mathrm{B}}(\mathrm{W})$ of the hydraulic pump are respectively calculated by Eqs. (1) and (2) after expressing them in the International System of Units (SI) by:

$$
\begin{aligned}
& P_{-} F=D_{F} \cdot\left(P_{F}-P_{B}\right) \\
& P_{-} B=D_{B} \cdot\left(P_{F}-P_{B}\right)
\end{aligned}
$$

where $P_{\mathrm{F}}$, and $P_{\mathrm{B}}$ are respectively the forward and back pressures $(\mathrm{Pa})$ of the hydraulic pump and $D_{\mathrm{F}}$ is pump forward mass flow $\left(\mathrm{m}^{3} / \mathrm{sec}\right), D_{\mathrm{B}}$ is pump back mass flow $\left(\mathrm{m}^{3} / \mathrm{sec}\right)$.

\section{Electrified Hybrid Architecture Modeling and Control Strategy}

In this section, an electrical model of a fully electrified hybrid propulsion chain of a bow thruster, implemented using Matlab/Simulink ${ }^{\circledR}$ modeling is presented. This modeling lies on the use of the power electronic components models such as power converters (3-phase PWM voltage source inverter) and supercapacitors buffer storage, in order to produce an electrical energy to feed the electrical machine for the propulsion of the bow thruster. The AC motor involved is a high power 3-phase permanent magnet synchronous machine (PMSM) with smooth rotor poles ( 2 pole pairs), no saturation effects were considered. PMSM machine will mainly operate in direct drive during the short time intervals when the bow thruster is applied to filling the maneuver of docking, undocking and positioning. PMSM 
technology is preferred for the motor, in competitive comparison with the synchronous machine with field rotor excitation. The synchronous motor with field rotor excitation requires an external field circuit, which solution goes against the optimization of space, weight and cost. Synchronous technologies for the AC motor are preferred in this application (medium power range) to asynchronous one [16]. Indeed, synchronous AC motor technologies lead to a high mass/volume power ratio for the range of specifications, dynamic performance, but also improved efficiency, and the implementation of an easier control strategy.

\subsection{Electrical Hybrid Architecture with} Supercapacitors-Based Buffer Energy Storage

The proposed power propulsion chain of the bow thruster firstly consists in a DC voltage source (a battery bus with $600 \mathrm{~V}$ DC voltage amplitude). This electrochemical battery already exists in the boat, and also feeds other systems such as the alarm system, lighting, other onboard and power conditioning auxiliaries, etc.). Then, this DC battery is associated to an input filter capacitor coupled to a system of electrical energy storage based on $N$ supercapacitor cells ( $N=100$ cells of supercapacitors fully charged to $270 \mathrm{~V}$ ) through a reversible DC/DC converter. Eq. (3) gives the expression of the buffer storage energy (Wh):

$$
E=N \cdot \frac{1}{2} C U_{0}^{2}=P_{\max }(k W) \cdot \Delta t
$$

With $C=5,000 \mathrm{~F}$ the capacitance, $U_{0}(\mathrm{~V})$ the supercapacitor single cell voltage, according to Eq. (3), to achieve $P_{\max }=200 \mathrm{~kW}$ in $\Delta t=9.11 \mathrm{~s}$, the energy delivered by the buffer supercapacitor storage should be $E=506 \mathrm{Wh}$.

Both DC sources are connected to a 3-phase voltage PWM inverter which supplies the PMSM driving the bow thruster (engine-propeller system). It will be shown in the following how it is possible to wisely manage both full electric sources to manage bow thruster's torque high constraints. Analytical models for each of the individual propulsion components were implemented and incorporated into a complete hybrid electric propulsion model. As it is shown in Fig. 3a, an on-board DC-source (Battery bus) is associated to the buffer energy storage system composed of supercapacitors modules and their reversible DC/DC converter interface (IGBT (Insulated Gate Bipolar Transistor)/Diodes-based Step-Up)). Both sources are connected through a current node to a 3-phase IGBT/Diodes PWM voltage source inverter [17].

Fig. $3 \mathrm{~b}$ presents the hybrid electrical converter system with the addition of two IGBT/Diode semiconductor switches which are activated for the source (DC bus, or supercapacitors) management with

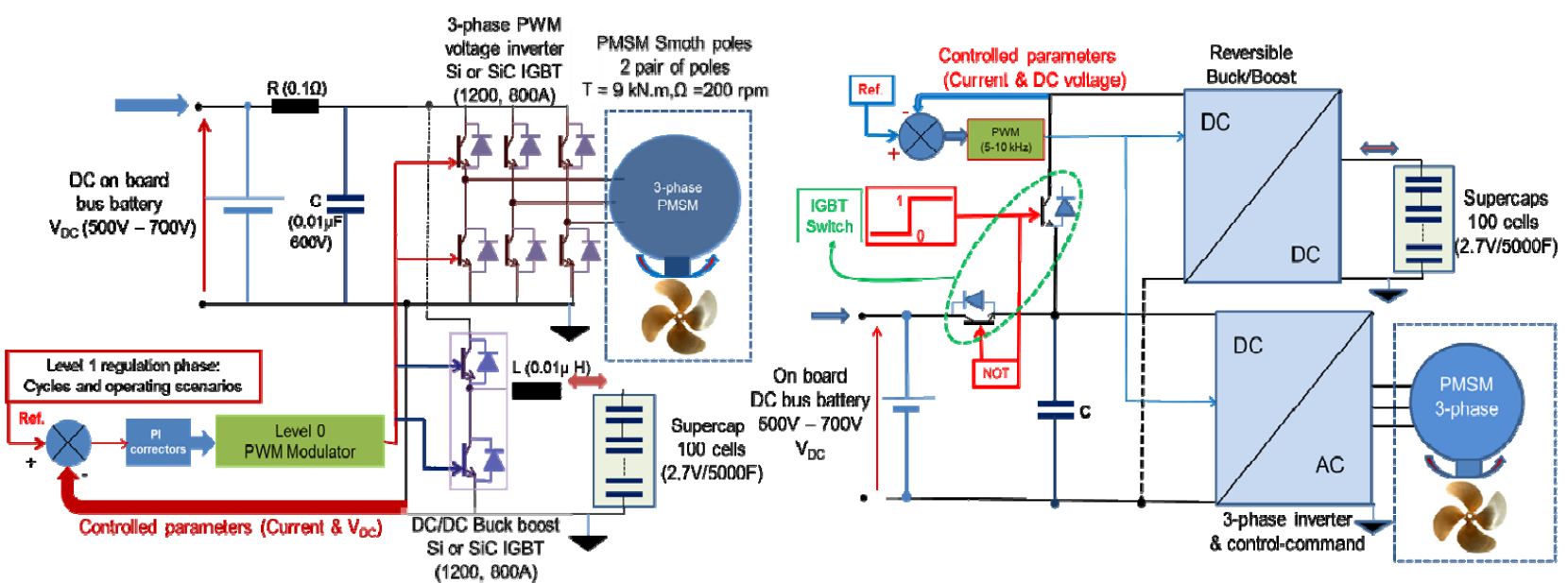

(a)

(b)

Fig. 3 (a) General powertrain architecture for electrified bow thruster; (b) Switches for the power sources management. 
respect to the load demand or Supercapacitors recharging phase. The IGBT/Diode is controlled by the management interface.

\subsection{Torque Control Strategy}

As is already known, a bow thruster only operates during maneuvers of docking and undocking and requires high torque amplitude for low rotation speed and during relatively short periods of time (tens of seconds). This relates to an auxiliary or subsystem propulsion in which dynamic operation characteristic differs from the full riverboat main propulsion system. Therefore, it is crucial for the PMSM motor-propeller assembly to achieve the high torque value required during these operations. For these short time intervals, the current is provided by the supercapacitors buffer energy tank, in order to release the current constraints of on-board DC bus. Hence, in the modeling stage, the control strategy lies first on the motor-propeller torque control $\left(\mathrm{T}^{*} \mathrm{Nm}\right)$ and second, on the control of the supercapacitors current, in which reference value $\left(I_{\mathrm{sc}}{ }^{*}\right)$ is deduced from the maximum of motor mechanical power $\left(P_{\max }\right)$ and DC bus voltage amplitude $(600 \mathrm{~V} \mathrm{DC}$ rated, with range between $500 \mathrm{~V}$ and $700 \mathrm{~V}$ ) as shown by the control law synopsis in Fig. 4. More specifically, for the control strategy, the motor torque of the bow thruster is controlled (at a torque reference value of $\mathrm{T}^{*}$ $=9,000 \mathrm{Nm}$ ) to provide the power to the bow thruster. The output of the torque regulator provides the phase current amplitude to the power system. The 3-phase currents are controlled in the Park $(\mathrm{d}, \mathrm{q})$ rotor frame, with $I_{\mathrm{q}}$ component being the image of the dynamic electromagnetic torque. Neglecting the start-up (acceleration) and shut-down (deceleration) phases of the motor propeller, and during the short periods of operating time, regarding the torque control algorithm issue, the motor speed can be approximated as constant (200 rpm). The global control uses an intersected PWM based strategy at $5 \mathrm{kHz}$ switching frequency for the inverter, as seen in Fig. 4.

As it can be seen in Figs. 3a and 4, this approach involves two levels of regulation: the level 0 (micro level) is the PWM regulator which generates the command duty-cycles to the DC/AC inverter IGBTs and the level 1 (macro level) which is the torque regulator.

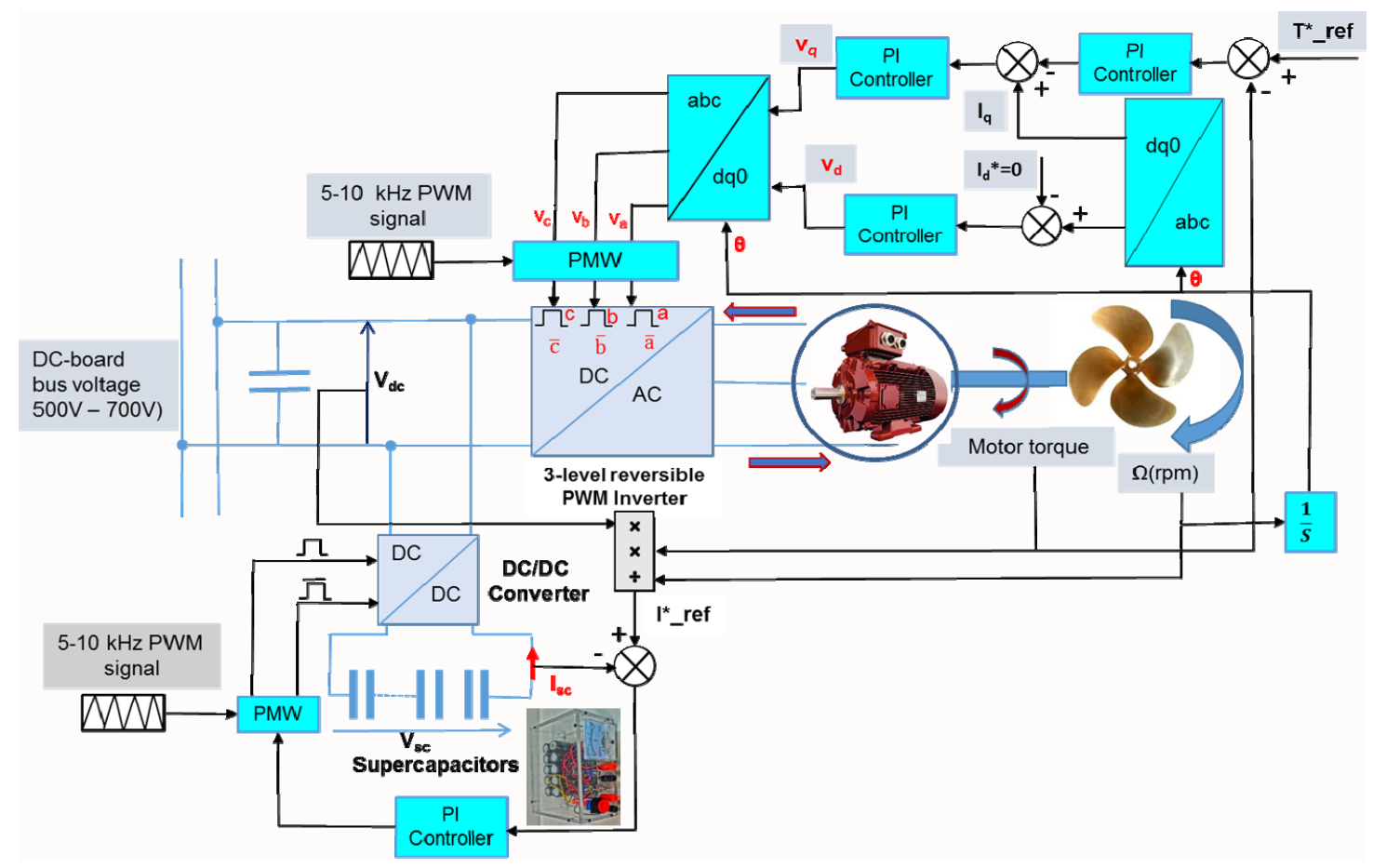

Fig. 4 Electrical bow thruster propulsion chain with torque control law. 


\subsection{Power Sources Management between DC-Bus Battery and Supercapacitors}

In this section, we describe the strategy implemented to optimize the use of the two power electric sources.

One of the advantages of the use of two different electric sources lies on their alternate and optimized operating. The idea is to minimize the solicitations on the DC bus network, using supercapacitors during high torque peak constraints phases as it is shown in Fig. 5. This wise management of these power sources should respect the trigger operating condition, i.e. supercapacitors operating voltage should not drop below half of the maximum of supercapacitors preloaded charge voltage. It should also be pointed out that supercapacitors constitute the best suited dynamic power source with respect to the application like bow thruster requiring high torque, low speed, which operates during short periods of time. In addition, the enlarged utile area for supercapacitors is flexible, nevertheless depending on their discharge ratio. Then, the DC bus battery is used to power bow thruster only when torque nominal value is reached as it is shown in the photography which illustrates the dynamic storage operating sequences involving two sources.

Hence, thanks to the insertion of an IGBT/Diodes controlled half-bridge, based on 2 reversible semiconductor switches, the two power electric source managements can be achieved as depicted in Figs. $3 b$ and 5.

\section{Simulation Results}

This section is dedicated to the simulation results issued from the analytical modeling of the complete bow thruster propulsion system. The motor torque is determined from the peak mechanical power level $\left(P_{\max }\right)$, rotating speed $\Omega$ and electrical motor characteristics. The torque reference for the control loop is set to $9,000 \mathrm{Nm}$ for a peak power value of 200 $\mathrm{kW}$. The rotational speed of the PMSM motor is assumed to be constant at $200 \mathrm{rpm}$ regarding torque control algorithm requirements. For the load (the propeller), strong power amplitude curve is used as power demand for the propeller, and at a low speed (200 rpm). Indeed, it is the curve power/speed of a high power PMSM motor which has been used. This power curve is given by the measured data. Simulation results in Fig. 6, show torque regulation following the reference, and for two rotational directions (direct-reverse) of the propeller. A focus is done on the three PMSM sinusoidal phase currents. The power supply architecture has been adequately sized and designed for the specific riverboat energetic propulsion. These constraining load profiles in which high powers are required to provide a necessary motor propelling torque during relatively short time intervals are illustrated in Fig. 2a. Real monitored data are provided to illustrate the mission profile of the bow thruster. The energy storage system based on high capacitance 5,000 F supercapacitor cells is sized for the peak power. Thus, the electrification using hybridization is justified by the power constraints of the bow thruster system illustrated by significant torque peaks. Indeed, the bow thruster is used at full peak power $(200 \mathrm{~kW})$ only during small periods of time (several tens of seconds, depending on the tugboat maneuver). Hence, the power supply from the battery on-board DC bus can be assisted by the electrical buffer storage (supercapacitors) to supply the bow thruster motor and consequently relieve the electrical constraints on the DC on-board Battery bus.

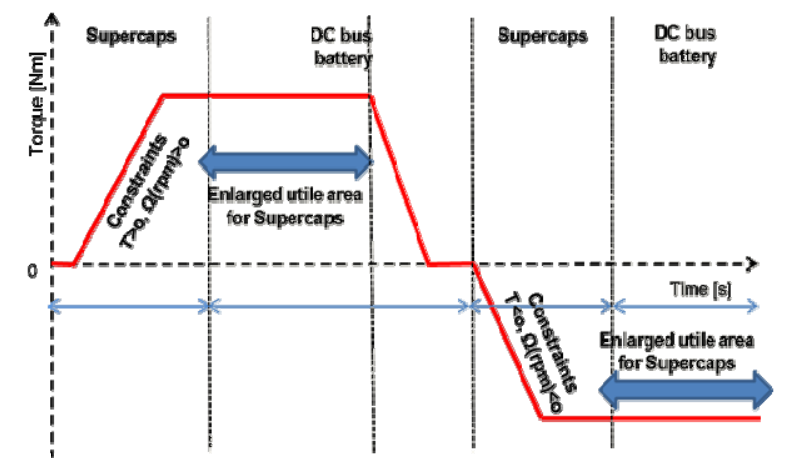

Fig. 5 Dynamic storage operating sequences involving DC bus battery and supercapacitors. 


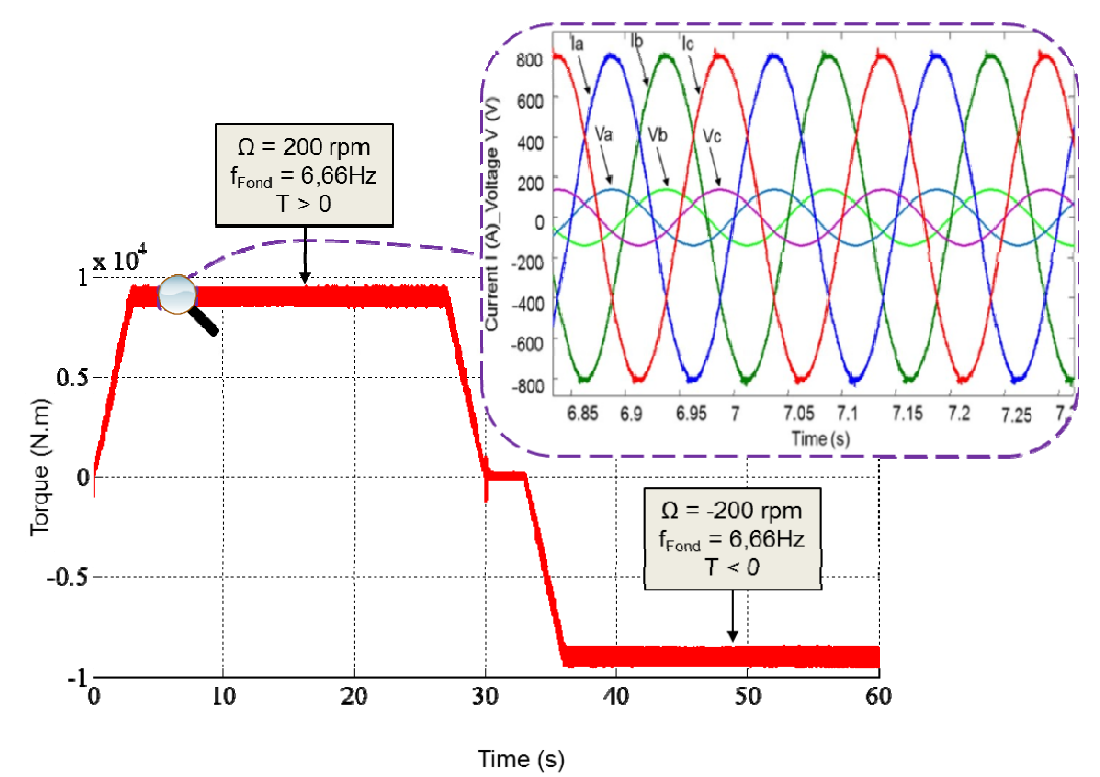

Fig. 6 PMSM torque regulation and focus on the 3-phase sinusoidal currents $\left(I_{\mathrm{a}}, I_{\mathrm{b}}, I_{\mathrm{c}}\right)$ and reference phase voltages $\left(V_{\mathrm{a}} *, V_{\mathrm{b}} *\right.$, $\left.V_{\mathrm{c}}^{*}\right)$.

Focus in Fig. 6 shows the waveforms of PMSM voltages and current level in the different phases. As it can be noticed, the 3-phase voltage PWM DC/AC inverter accurately regulates, as well as phase voltage and current waveforms are set in phase by the control strategy in order to achieve maximal torque and limited losses.

Indeed in this study, iron, hysteresis and friction losses of the Permanent magnet synchronous motor (PMSM) are supposed neglected. Moreover, the current control strategy using the rotor position, and vector control-based, enables to set in phase the reference voltages $\left(V_{\mathrm{a}}^{*}, V_{\mathrm{b}}{ }^{*}, V_{\mathrm{c}}^{*}\right)$ and the PMSM three-phase currents $\left(I_{\mathrm{a}}, I_{\mathrm{b}}, I_{\mathrm{c}}\right)$ as shown in Fig. 6, which permits to operate at maximal torque and minimize copper (Joule) losses in the motor with no phase-shift between PMSM back-emfs (back-electromotive forces) and phase currents.

Furthermore, torque, supercapacitors voltage and current, and DC bus battery current waveforms are summarized in Fig. 7. The top left figure shows the different high peak torque constraints of the motor and the bottom left graph shows supercapacitors voltage waveform whether they are used in discharge or in charge. As it can be seen, when the PMSM machine is used in direct drive, the supercapacitors initially preloaded, are firstly solicited in order to provide the required current amplitude to feed the $\mathrm{AC}$ motor for achieving the high torque demand.

During this sequence of supercapacitors operating, (from 0 to 10 seconds), their voltage drops, reflecting their discharging as shown in Fig. 7 (bottom left graph). Once the torque reaches its rated value, the battery bus takes over (from 10 to 40 seconds), while recharging the supercapacitor cells and supplying the bow thruster powertrain, the supercapacitors voltage increases reflecting their recharge state. At $t=33 \mathrm{~s}$, when the second torque transient becomes negative, the supercapacitors discharge in order to provide a high amplitude power peak, and the DC-bus contribution is kept restrained. The supercapacitors discharge then until $t=50 \mathrm{~s}$, then the DC-bus recharges the energy storage elements, to be fully charged for initiating a new load profile. The top and bottom right graph respectively show supercapacitors current $\left(I_{\mathrm{sc}}\right)$ and DC bus current $\left(I_{\text {bat }}\right)$ waveform following the dynamic torque sequences depending on whether they are in use or not. This proposed strategy shows that supercapacitors may be required to supply the bow thruster, during the start-up of torque strong constraints, before handing 

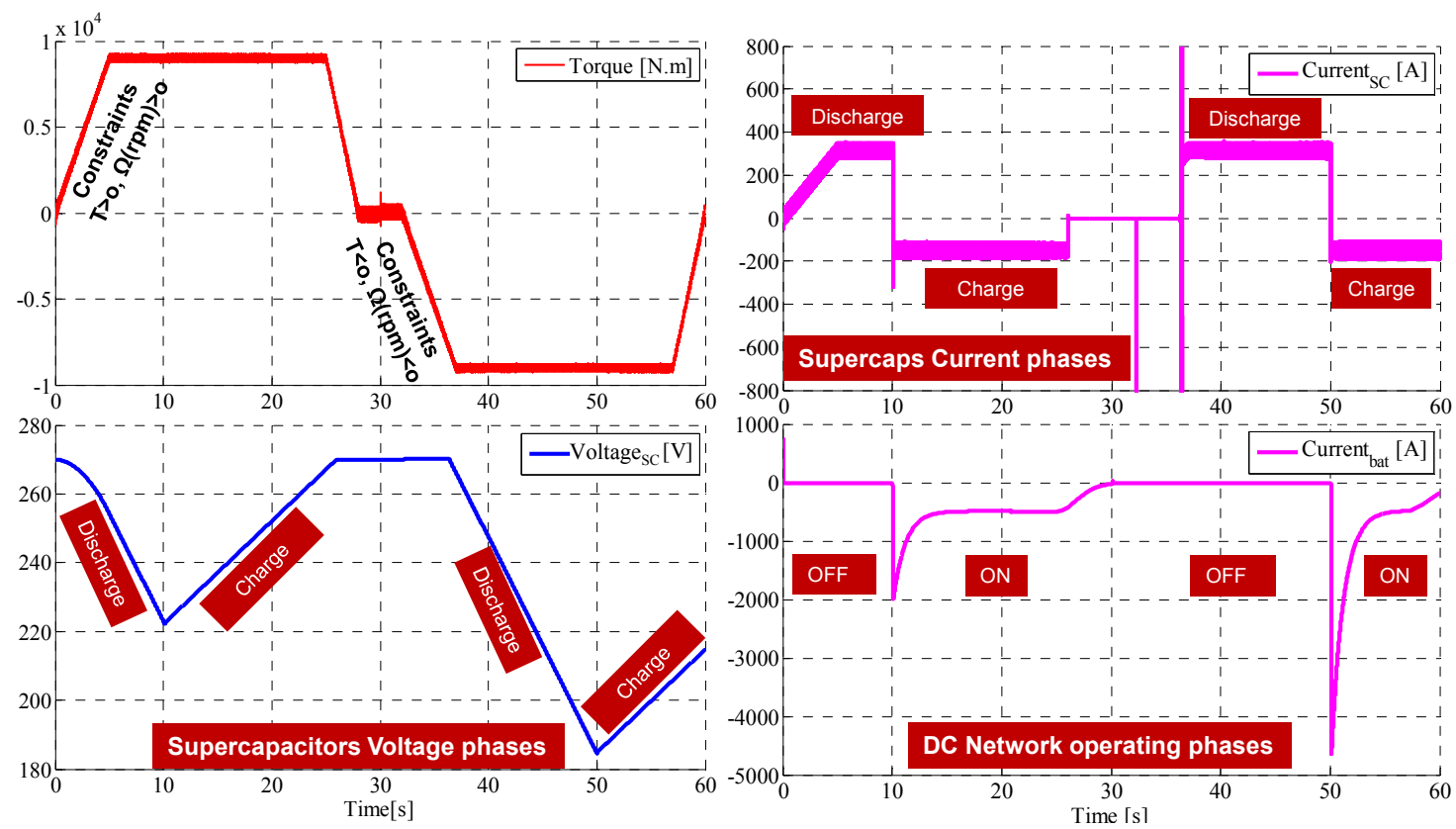

Fig. 7 Torque, supercapacitor's current and voltage waveforms, and DC battery bus current over a full running cycle of the bow thruster.

over to the battery bus when the nominal value of the required torque is reached. The supercapacitors will then have characteristic charge and recharge cycles as they are used to power the bow thruster motor or not. The supercapacitor behavior demonstrates the accurate control operation according to the working expectations. The charge/recharge strategy is practically achieved thanks to the use of added and synchronized IGBT switches in the power circuit. In Fig. 7, the supercapacitors behavior during the full operating cycle of the bow thruster, which consists in supercapacitors discharge and recharge phases, is shown.

Hence, to calculate the system efficiency, Eq. (4) has been considered. This efficiency $(\eta)$ calculation has been realized in direct drive mode, in which the total current amplitude is provided by the supercapacitors during constraints phases. This causes the discharge of supercapacitors before the DC onboard battery bus takes over and recharges the supercapacitors.

$$
\eta=P_{-} \text {motor } / V_{-} \text {bus }\left(I_{\text {bus }}+I_{S C}\right)
$$

where $P_{\text {motor }}$ is the PMSM mechanical power, $V_{\text {bus }}$, the DC bus voltage, $I_{\text {bus }}$ the DC bus current and $I_{\mathrm{sc}}$ is the supercapacitors current. The efficiency calculation which consists of both discharge and charge efficiencies, during a full bow thruster operating cycle, ( $\eta$ ) gives a value of about $90 \%$ for a charge-discharge cycle. Considering the global efficiency calculation, the losses from the DC-AC and DC-DC power conversion stages should be estimated towards 3 to $5 \%$ of the transmitted power, reducing hence, the global efficiency to a maximum of 85 to $87 \%$.

\section{Test Bench for Bow Thruster-Emulator: Current Control Strategy Validation}

SATIE/IFSTTAR laboratory has been recently equipped with an adaptable test-bench platform able to test hybrid drive powertrains at a reduced power scale and composed of modular power systems. For this application, the scale ratio is less than or equal to $1 / 12$ (electrical motors have $17 \mathrm{~kW}$ maximal power). The objective of the actual experimental part is to be able to emulate the bow thruster powertrain and provide first practical results. First results to be performed on the test bench are the PMSM1 current control strategy issue. The synoptic of the bow thruster power train is 
presented in Fig. 8. The powertrain is composed of two stages both equipped with identical $17 \mathrm{~kW}, 6,000 \mathrm{rpm}$ CMP80L PMSM from German SEW Company. The first stage represents the assembly DC/AC inverter with PMSM1, the main propulsion motor of the bow thruster. The second stage emulates the bow thruster propeller and allows imposing a resistive torque thanks to a PMSM2 connected to a three-phase industrial controlled rectifier Movidrive ${ }^{(}$and a dissipative 18

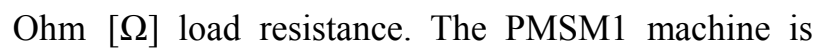
torque controlled via the $\mathrm{DC} / \mathrm{AC}$ inverter using a $5 \mathrm{kHz}$ intersected PWM control strategy. PWM duty-cycle signals are generated by a rapid prototyping unit from dSPACETM, based on an ultra-fast DS1006 Processor card and DS5202 FPGA (Field Programmable Gate Array) Base-board. PWM-Duty cycles are generated using an analytical formula following Eq. (5) knowing the $V_{\mathrm{DC}}$ Bus voltage amplitude and reference modulation phase voltage $\left(V_{\bmod }{ }^{*}\right)$ for the intersected PWM method. Then, the duty cycles are conditioned through the dSPACE PWM Sine Commutation ${ }^{(}$Block to the Gate signals of the DC/AC inverter.

$$
d=\frac{1}{2} \cdot \frac{V_{\text {mod }}^{*}}{V_{D C}}+\frac{1}{2}
$$

PMSM1 3-phase currents are measured and displayed on the ControlDesk $^{(}{ }^{(}$interface via an ADC conversion block. The angular rotor position $\left(\theta_{\text {mech }}\right)$ used for the control is deduced from the output of a $\sin / \cos$ resolver (RH1M) integrated in the PMSM stator and using the Resolver Input Block of dSPACE. Synoptic of the PMSM1 Torque control using dSPACE prototyping interface is given in Fig. 9.

The storage elements are composed of Supercapacitors modules (5,000 F, 2.7 V) connected through their electric interface to the variable DC-bus voltage (from 0 to $800 V_{\mathrm{DC}}$ ). The resistive torque reference is hence imposed by the second stage with the industrial rectifier. The dSPACE system generates the control of the PMSM1 three-phase sinusoidal currents, which emulate the electromagnetic torque $T$ $(\mathrm{Nm})$ of the propulsion machine. Fig. 10 illustrates the test bench setup at reduced power realized at IFSTTAR laboratory. For data acquisition a fast speed numerical recorder Yokogawa ${ }^{(C)}$ is used, which enables to acquire the phase currents and PWM gate control signals. Data acquisition for the PMSM1 phase currents from the numerical oscilloscope recorder is provided in Fig. 11.

The test bench is equipped with a torque meter from $\mathrm{HBM}^{\circledR}$ mounted and equilibrated on the powertrain shaft between PMSM1 and PMSM2 with a maximal measuring range capability of $T_{\operatorname{maxHBM}}=100 \mathrm{~N} \cdot \mathrm{m}$. Thus, for a rotational speed of $200 \mathrm{rpm}=20.93 \mathrm{rad} / \mathrm{s}$, the developed mechanical power is limited to $P_{\mathrm{mec}}=2$ kW. PMSM1 phase currents are correctly controlled following the current reference waveforms in the

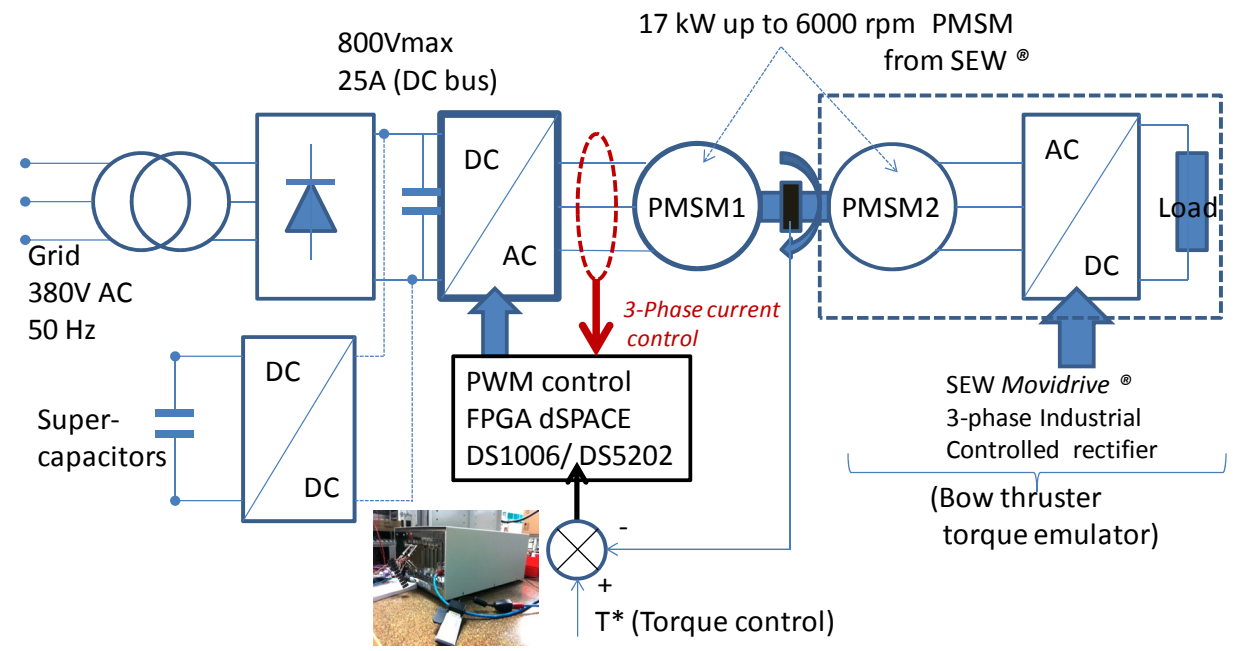

Fig. 8 Synoptic of the experimental test bench emulating the bow thruster (propeller) chain with torque control. 


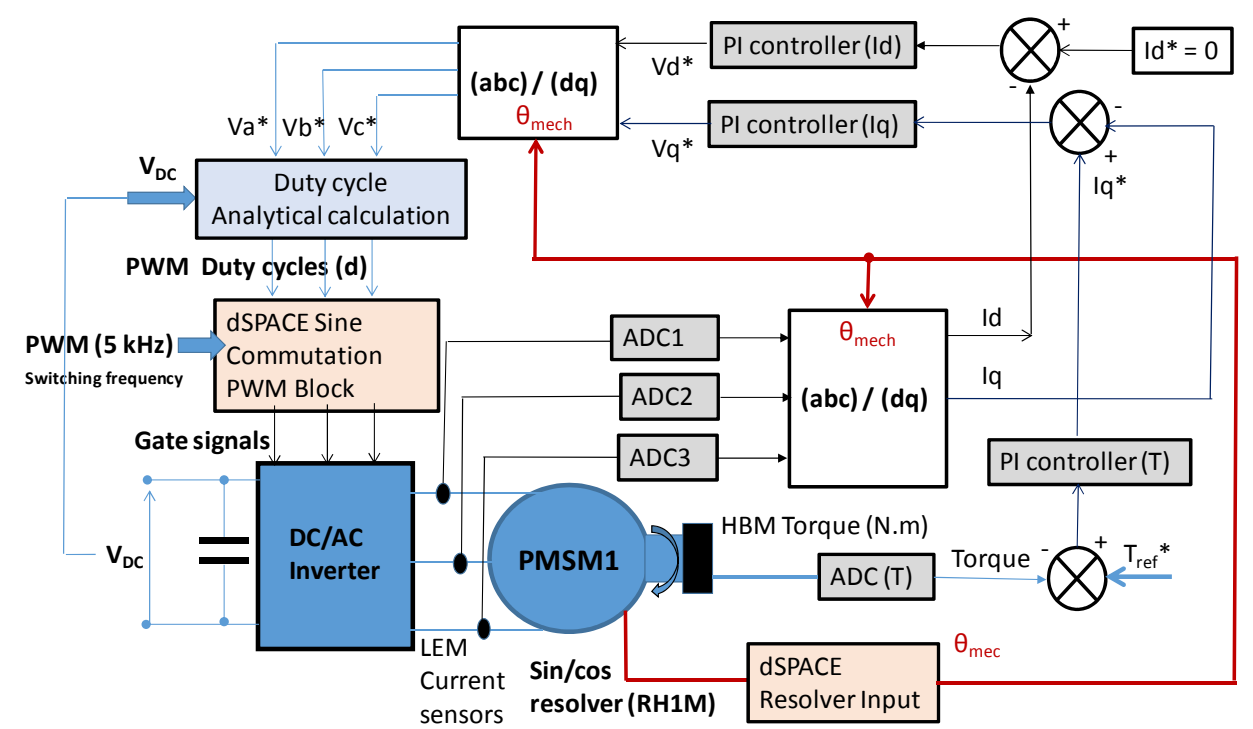

Fig. 9 Synoptic of the PMSM1 Torque control using dSPACE prototyping interface.

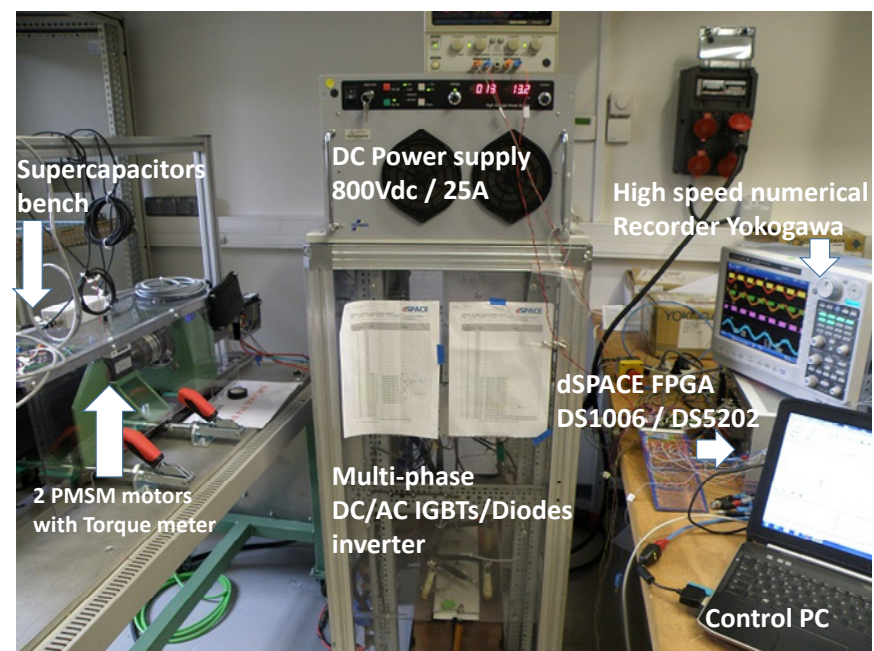

Fig. 10 Test bench set-up realized at SATIE/IFSTTAR.

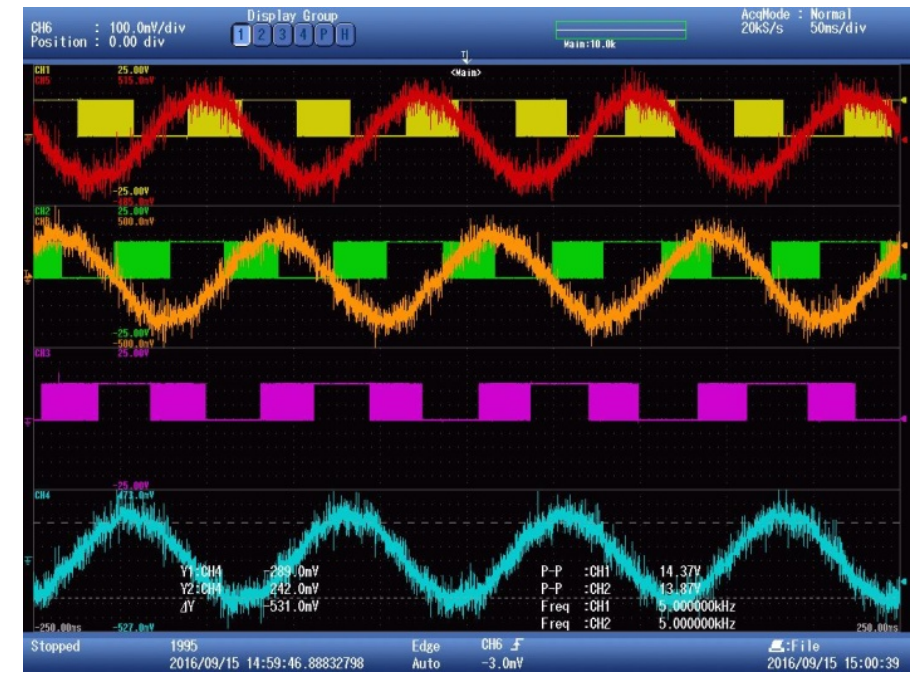

Fig. 11 Numerical scope recorder Yokogawa: PWM signals (5 kHz) and PMSM1 currents for $2 \mathrm{~kW}$ test at $200 \mathrm{rpm}$. 
Table 2 Technology and unitary cost/elements of integrated semiconductor power devices, supercapacitors, and permanent magnet synchronous machine for electrified bow thruster prototype.

\begin{tabular}{|c|c|c|c|}
\hline Component & Technology & Size / caliber & Estim. cost \\
\hline \multirow[t]{2}{*}{ 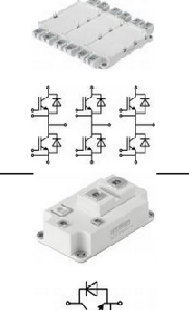 } & $\begin{array}{l}\text { 3-phase reversible } \\
\text { Inverter } \\
\text { + DSP Card }\end{array}$ & $\begin{array}{c}1200 \mathrm{~V}, 900 \mathrm{~A} \\
5-20 \mathrm{kHz} \\
(\approx 4,000 €) \\
\text { Control, } Q \mathrm{Qcontrol} \text { Software } \\
(\approx 2000 €)\end{array}$ & $\begin{array}{c}6.000 € \\
\approx \\
6.756 \text { USD } \\
\begin{array}{c}\text { Semikron/lnfineon } \\
\text { Mitsubishi }\end{array}\end{array}$ \\
\hline & $\begin{array}{c}\text { Roversiblo Buck Boost } \\
\text { + DSP Card }\end{array}$ & $\begin{array}{c}900 \mathrm{~A} / 5-20 \mathrm{kHz} \\
1200 \mathrm{~V} \leftrightarrow(270,135 \mathrm{~V}) \\
+ \\
\text { Control, Qcontrol Software }\end{array}$ & $\begin{array}{c}6.000 € \\
\approx \\
6.756 \text { USD } \\
\text { Semikron/Infineon } \\
\text { Mitsubishi }\end{array}$ \\
\hline \multirow[t]{2}{*}{2 2N:50\% } & Supercapacitors & $\begin{array}{c}50-100 \text { cells } \\
2.7 \mathrm{~V} \text { 5000F/5- } 20 \mathrm{kHz}\end{array}$ & $\begin{array}{c}8.300 € \\
\approx 1.6 \mathrm{ct} \epsilon / \mathrm{F} \\
9.346 \mathrm{USD} \\
\text { Bolloré/Maxwell... }\end{array}$ \\
\hline & PMSM & $\begin{array}{l}600 \mathrm{~V} 250 \mathrm{~kW} \\
\text { Low speed rpm } \\
2-4 \text { poles pairs }\end{array}$ & $\begin{array}{c}25.000 € \\
\approx 100 \mathrm{ct} € / / \mathrm{kW} \\
110 \mathrm{USD} / \mathrm{kW} \\
28.157 \mathrm{USD}\end{array}$ \\
\hline
\end{tabular}

control strategy. The propeller thanks to the reversible motor-converter powertrain is able to operate in both forward and reverse directions. Next step will be using this experimental set-up to reproduce scenarios representing working use cases of the propeller chain in correspondence to the monitored data on ship.

\section{Techno-Economic Aspects for a Full Electrified Prototype Solution}

The analysis of different solutions for actuation in-ship auxiliaries such as bow thruster or other on-board drives which are usually powered by oil-fed actuators shows the systematic use of hydrostatic transmissions when the highest torques/forces with low speeds are required. However, as discussed before, not only the oil production is too expensive, but oil presents environmental risks issues. Otherwise, the maintenance onboard ship issues are also recurrent. A full electric solution becomes then an essential requirement. With its high efficiency factors $(80 \%$ to $90 \%$ ), this approach only requires a 3-phase PWM-VSI voltage source inverter (designed from the association of reversible IGBT/Diodes which are a 1,200 V-600 A calibers device) and a DC-DC converter (reversible IGBT/Diodes-based step-up chopper) coupled to the supercapacitor tank. Due to high current amplitudes in the PMSM phases, using for e.g. discrete semiconductors (1,200 V-900 A) from Semikron ${ }^{\circledR}$, Infineon ${ }^{\circledR}$ or Mitsubishi ${ }^{\circledR}$ technology would be a solution. The different technology way of power components and modules, as well as the synchronous motor and energy storage system which can be considered in this study are summarized in the non-exhaustive Table 2. Techno-economic aspects are here concerned for the design of a bow thruster system prototype, and to be provided for the new full electrical solution. For the newly designed system, the supercapacitors, and motor-propeller in generating mode can recharge the DC-bus battery of the systems, hence avoiding the consumption of more fuel for recharging the batteries (like for the hydraulic-conventional solution).

This investigation highlights on the one hand, an excellent cost/performance compromise which significantly reduces the cost for the generation of energy compared to conventional hydraulic system (cost of two converters with supercapacitors estimated at about $10 \mathrm{k} €$, including a $0.4 \mathrm{mH}, 400 \mathrm{~A}$ self-inductor). So global candidate cost is about $45,300 €$ (49,830 USD). On the other hand, the energy generation becomes more environment-friendly. Already these two advantages motivate this full electric solution. Anyway there are also some other possible benefits: the increased dynamic performance, the 
reduction of network use fees and the reduction of maintenance and expansion costs for the fuel consumption. In addition to other good features, PMSM has better control performances thanks to full electric solution. Torque limitation function can be directly embedded in the electronic drive control strategy. Nevertheless, copper, friction and iron losses are the main limiting factors in developing the electrified version of bow thruster at low speed. They represent the main obstacle (hurdle) to direct drive full electric application.

\section{Conclusions}

The proposed electrification solution of a bow thruster subsystem for a river tugboat is based on a full electrified hybrid concept which enables to have direct $\mathrm{DC}$ to AC current conversion from the onboard battery DC bus to the propeller motor with about $90 \%$ efficiency. Simulation results, based on real monitored data values, were obtained for characteristic working modes of the bow thruster implying high torque values at low propulsion speed. All the numerical simulations outcomes, based on an analytical modeling of the bow thruster propulsion chain with torque control strategy are very encouraging and demonstrated that the electrification solution be realistic. Many benefits and potential applications will accrue using this concept. In particular, the originality of the proposed electrified hybrid solution is to take the best advantage of the supercapacitors dynamic performances during the initial high torque transients. The supercapacitors buffer energy storage solution will relieve the electric constraints on the onboard battery used to supply the bow thruster motor chain when the required torque attains its rated value. The DC battery bus powering the motor, also simultaneously recharges the supercapacitors modules. The study shows the possibility to manage the operating sequences of the two DC electrochemical power sources: Battery and supercapacitors. An experiment in laboratory at a reduced power scale has permit to emulate the current control strategy of the electrical motor-propeller phase currents using a Pulse Width Modulation torque control strategy. In addition, the techno-economic aspect for first prototype demonstrates the cost issues for the proposed full electrified hybrid solution, which should be stated as a viable and realistic green solution for potential industrial development. Hence, further works are still be carried out in order to optimize the global bow thruster propulsion system and its associated commercial costs.

\section{Acknowledgments}

Authors gratefully thank the European Funds for Regional Development (FEDER) under grant Presage 41189/41192, and French Region of Rhône-Alpes for funded the PROMOVAN project (2012-2015) and VNF, CFT companies, CEA for data monitoring and recording for the bow thruster on-board the tugboat.

\section{References}

[1] Biresaw, G., and Erhan, S. 2008. "The Organization for Economic Co-operation and Development." International Transport Forum, Greenhouse Gas Reduction Strategies in the Transport Sector: Preliminary Report.

[2] Sudhoff, S. D. 2011. "Currents of Change." IEEE Power and Energy Magazine 9 (4): 30-7.

[3] Ådnanes, A. K., and Wolak, B. 2004. "Status and Inventions in Electrical Power and Thruster Systems for Drillships and Semi-submersible Rigs." In Dynamic Positioning Conference (DPC), Houston, September 28-30, 2004.

[4] Sørensen, A. J., Ådnanes, A. K., Fossen, T. I., and Strand, J.-P. 1997. "A New Method of Thruster Control in Positioning of Ships Based on Power Control." IFAC Proceedings Volumes 30 (22): 199-206.

[5] Castellan, S., Menis, R., Tessarolo, A., and Sulligoi, G. 2014. "Power Electronics for All-Electric Ships with MVDC Power Distribution System: An Overview." Ecological Vehicles and Renewable Energies (EVER), Ninth International Conference IEEE, Monte Carlo, pp. 1-7.

[6] Palczynska, B., Spiralski, L., and Wyszkowski, J. 2007. "Electromagnetic Field Measurements of Bow Thruster Drive with Frequency Converter." Presented at 5th International conference Workshop Compatibility Power Electronics, Gdańsk, Poland, on IEEE Conference Publications. 
[7] Sørensen, A. J., Quek, S. T., and Nguyen, T. D. 2005. "Improved Operability and Safety of DP Vessels Using Hybrid Control Concept." OSV Singapore.

[8] Sørensen, A. J., and Ådnanes, A. K. 2005. "Reconfigurable Marine Control Systems and Electrical Propulsion Systems for Ships." ASNE Reconfiguration and Survivability Symposium, Florida, USA.

[9] Bruzzese, C., Tessarolo, A., and Piva, L. 2004. "An Innovative Environmentally-Friendly Full-Electric Drive Solution for the Actuation of Shipboard Loads: Analysis Based on Prototype Testing Results." In IEEE 9th Ecological Vehicles and Renewable Energies (EVER), Ninth International Conference.

[10] Bruzzese, C. 2012. “Direct Drive of Ship's Steering Gears through Permanent-Magnet Linear Motors Featuring High Thrust and Efficiency." Power Electronics, Drives and Energy Systems (PEDES), IEEE International Conference on., Bengaluru, India.

[11] Backlund, P. B., Seepersad, C. C., and Kiehne, T. M. 2015. "All-Electric Ship Energy System Design Using Classifier-Guide Sampling." Transportation Electrification, IEEE Transactions 1 (1): 75-85.

[12] Sulligoi, G., and Rathore, A. K. 2016. "Guest Editorial Marine Systems Electrification." IEEE Transactions on Transportation Electrification 2 (4): 504-6.

[13] Sulligoi, G., Vicenzutti, A., and Menis, R. 2016. “All Electric Ship Design: From Electrical Propulsion to Integrated Electrical and Electronic Power Systems." IEEE Transactions on Transportation Electrification 4: 507-21.

[14] Bucci, V., Marino, A., Bosich, D., and Sulligoi, G. 2016.
"Inland Waterway Gas-Fueled Vessels: CASM-Based Electrification of a Pushboat for the European Network." IEEE Transactions on Transportation Electrification 2 (4): 607-17.

[15] Zahedi, B., Norum, L. E., and Ludvigsen, K. B. 2014. "Optimized Efficiency of All-Electric Ships by DC Hybrid Power Systems." Journal of Power Sources 255: 341-54.

[16] Vaez-Zadeh, S., and Ghasemi, A. R. 2005. "Design Optimization of Permanent Magnet Synchronous Motors for High Torque Capability and Low Magnet Volume." Electric Power Systems Research 74 (2): 307-13.

[17] Moussodji, J., and De Bernardinis, A. 2015. "Electric Hybridization of a Bow Thruster for River Boat Application.” IEEE ITEC 2015 Conference, Dearborn, MI, USA, June 2015.

[18] Wu, J., Ye, J., Yang, C., Chen, Y., Tian, H., and Xiong, X. 2005. "Experimental Study on a Controllable Underwater Towed System." Ocean Engineering 32 (14-15): 1803-17.

[19] Nakamuraa, M., Kajiwarab, H., and Koterayamaa, W. 2001. "Development of an ROV Operated Both as Towed and Self-propulsive Vehicle." Ocean Engineering 28 (1): $1-43$.

[20] Ling-Chin, J., and Roskilly, A. P. 2016. "Investigating a Conventional and Retrofit Power Plant On-Board a Roll-on/Roll-off Cargo Ship from a Sustainability Perspective-A Life Cycle Assessment Case Study." Energy Conversion and Management 117: 305-18.

[21] Ling-Chin, J., and Roskilly, A. P. 2016. "A Comparative Life Cycle Assessment of Marine Power Systems." Energy Conversion and Management 127: 477-93. 